\title{
GRAHAM GREENE: MÉXICO, EL PAÍS DE LA INTOLERANCIA
}

Armando Pereira*

RESUMEN: En este ensayo se intenta seguir el viaje que Graham Greene realizó a México en la primavera de 1938, con el propósito de escribir un libro que diera cuenta de la persecución religiosa que el gobierno de Lázaro Cárdenas llevó a cabo en el sureste del país (Veracruz, Tabasco y Chiapas). La imagen de México que se deriva de Caminos sin ley es la de un país que, en nombre de la razón y de la ciencia, desplegó un régimen de intolerancia, persecución y despojo sobre una población cuya única falta consistió en sostener una creencia distinta a la del Estado.

\section{yos}

ABSTRACT: In this article, we follow the journey that Graham Greene took in Mexico in the Spring of 1938, while writing his book detailing religious persecution during Lazaro Cardenas' government in Southeast Mexico (Veracruz, Tabasco, and Chiapas). The image of Mexico from The Lawless Road is of a country that, in the name of reason and science, unleashed a regime of intolerance, persecution, and destitution on its inhabitants whose only fault was in having different beliefs from that of the State.

Palabras Clave: Graham Greene, México, intolerancia religiosa, Caminos sin ley, Lázaro Cárdenas.

KEY WORDS: Graham Greene, México, religious intolerance, The Lawless Road, Lázaro Cárdenas.

RECEPCIÓN: 7 de marzo de 2013.

APROBACIÓN: 2 de abril de 2013.

* Centro de Estudios Literarios, Instituto de Investigaciones Filológicas, UNAM. 
CITAM Derechos Reservados.

La reproducción total o parcial de este artículo se podrá hacer si el ITAM otorga la autorización previamente por escrito. 


\section{GRAHAM GREENE: MÉXICO, EL PAÍS DE LA INTOLERANCIA}

Durante la primavera de 1938 , Graham Greene realiza un viaje a México con el propósito de escribir un libro que dé cuenta de la persecución religiosa que todavía, durante el gobierno revolucionario de Lázaro Cárdenas, se seguía llevando a cabo en el país. Esa persecución religiosa tenía ya una larga historia de años o décadas atrás. Inspirada en las Leyes de Reforma de Benito Juárez (1855), que proclamaban la separación de la Iglesia y el Estado y confiscaban todas las propiedades eclesiásticas, Sebastián Lerdo de Tejada pondría en marcha la persecución en 1874, contra los "religioneros", grupos de campesinos pobres sin dirigencia visible, que se levantaban en armas, sobre todo en el centro y occidente del país, para defender su fe y sus iglesias, y que vendrían a constituirse en el antecedente directo de los cristeros. Al triunfo de la Revolución, primero con Venustiano Carranza y más tarde con los gobiernos de Álvaro Obregón y de su sucesor Plutarco Elías Calles, las disputas entre la Iglesia católica y el Estado liberal se recrudecerían y terminarían desembocando en la rebelión cristera. Todavía en 1938, con el gobierno de Lázaro Cárdenas, esas confrontaciones no habían desaparecido, continuaban sobre todo en los estados del sur: Veracruz, Tabasco y Chiapas. ${ }^{1}$ Hacia allí se dirigía Greene para cumplir con el encargo de su editor inglés: escribir ese libro que diera cuenta de la intolerancia religiosa del gobierno revolucionario

${ }^{1}$ Para una información más amplia sobre este período, cfr. Jean Meyer, La cristiada. El conflicto entre la Iglesia y el Estado, 1926-1929, 1978, México, Siglo XXI editores. 
de México. El libro se publicaría en Inglaterra bajo el título de The Lawless Roads y, simultáneamente en Estados Unidos, con el título de Another Country. El propio Graham Greene, refiriéndose a ese libro en el segundo tomo de sus memorias, ha señalado:

Caminos sin ley no es una novela, sólo una impresión personal de una pequeña parte de México en un momento particular, la primavera de 1938, poco después de que el país había sufrido, a manos del presidente Calles -en nombre de la revolución-, la más fiera persecución religiosa que se hubiera visto en cualquier otra región, desde el reinado de Elizabeth. ${ }^{2}$

Sin embargo, su interés por México no nació en 1938, a instancias de un simple encargo editorial, sino muchos años atrás, cuando ni siquiera se imaginaba que algún día se convertiría en escritor. Siendo todavía un niño, a los diez años de edad, había leído un libro (La hija de Moctezuma de Henry Rider Haggard) que lo había llevado a interesarse en la historia de México. Varias décadas más tarde, anotaría en el primer volumen de sus memorias: "Y seguramente debe haber sido La hija de Moctezuma y la historia de la desastrosa noche de la batalla en retirada de Cortés los que me indujeron, veinte años después, a viajar a México". ${ }^{3}$

La infancia de Graham Greene transcurriría en el seno de una familia de ideas liberales, para la que los ritos y las ceremonias religiosas carecían de significación y estaban ausentes de su despreocupada cotidianidad: "para nosotros -anota el escritor inglés en sus memorias-, la víspera de Nochebuena no tenía significación alguna... No recuerdo ningún árbol de Navidad en nuestra casa". ${ }^{4}$ Su inesperada conversión al catolicismo ocurrió en Nottingham, en 1926, cuando acababa de cumplir veintidós años. Aunque varios críticos ${ }^{5}$ señalan que esta conversión se debió úni-

${ }^{2}$ Graham Greene, Ways of Escape, 1999, London, Random House, Vintage, p. 81. Las traducciones son mías.

${ }^{3}$ Graham Greene, A Sort of Life, 1999, London, Random House, Vintage, pp. 40-1.

${ }^{4}$ Ibid., pp. 16-7.

${ }^{5}$ Cfr. Michael G. Brennan, "Graham Greene, Evelyn Vaugh and Mexico”, Renascence, 2002, Fall, 55 (1), pp. 7-23. 
camente al deseo de satisfacer la voluntad de su futura esposa, Vivien Dayrell-Browning, de casarse por la fe católica, las anotaciones de Greene al respecto en $A$ Sort of Life nos conducen en otra dirección, definitivamente mucho más verosímil. Sin duda, las creencias de su futura esposa serían determinantes para despertar la curiosidad intelectual de un joven que había crecido al margen de la fe: "mi religión no iba más allá de los sentimentales himnos de la capilla de la escuela, pero Vivien era católica. [...] Y si yo iba a casarme con una católica lo menos que podía hacer era conocer la naturaleza y los límites de sus creencias". ${ }^{6}$ Curiosidad intelectual, sí, pero su motivación sobre todo nacía del amor que sentía por ella y de la necesidad de comprenderla plenamente.

Una mañana de invierno, en la que saca a pasear a su perro, decide entrar a la Catedral neogótica de Nottingham y deposita, en una caja de madera en la que se solicitaba información, una breve nota manuscrita en la que pedía ser instruido en los "misterios de la fe". Así, entró en relación con el padre Trollope, con el que sostendría largas conversaciones una vez por semana que lo llevarían, después de varios meses, a convertirse a la fe católica. "Recuerdo que en enero de 1926 terminé convenciéndome de la probable existencia de algo que llamábamos Dios". 7 No serían sólo las conversaciones con el padre Trollope, sino también su decisiva inmersión en lecturas religiosas (en particular los libros del obispo Gore, en los que el sacerdote manifestaba sus propias dudas y tropiezos en el difícil camino de la fe), las que determinarían, a sus veintidós años, su voluntaria y definitiva conversión. En esa época, llegaría incluso a pensar seriamente en tomar los hábitos: "Descubrí en mí mismo lo que alguna vez el padre Trollope había descubierto: el deseo de ser sacerdote". ${ }^{8}$ Si no llegó a hacerlo fue porque no podía renunciar a su intenso amor por Vivien.

En la primavera de 1938, doce años después de su conversión, y ya en la frontera norte de México, Graham Greene se encontraba entonces en total posesión de una fe que lo acompañaría hasta el final de su

${ }^{6}$ Ibid., p. 118.

${ }^{7}$ Ibid., p. 120.

${ }^{8}$ Ibid., p. 122. 
vida. Y las escasas seis semanas que pasará recorriendo el sureste del país constituirán para él no sólo la confirmación de esa fe, sino su acentuación, su acendramiento. Durante su segundo viaje a México, en agosto de 1963, en una larga conversación con Raúl Ortiz, Greene responde enfáticamente a una de las preguntas del escritor mexicano: “¿Que por qué me expresé con tanta ira contra México? Tal vez porque aquí encontré la verdadera fé". 9

Pero ahora estamos en marzo de 1938 y el escritor inglés no ha cruzado aún la frontera. Está sentado en una de las plazas céntricas de Laredo, Texas, y lee plácidamente un periódico neoyorquino. De ahí nace la primera imagen de México que pondrá en marcha el discurso de Caminos sin ley y el propio viaje de su autor por nuestro territorio:

Había aquí tantas noticias sobre este país como en los diarios de Nueva York. En Nueva York mencionaban escaramuzas del otro lado de la frontera, frente a Brownsville: un individuo llamado el general Rodríguez había organizado a los granjeros descontentos, que perdían sus tierras, cedidas a los indios por las leyes agrarias, y formando con ellos una agrupación fascista llamada los "camisas doradas". Los diarios de Nueva York habían enviado reporteros especiales; uno de estos había tomado un taxi de Brownsville a Matamoros, y al volver había informado que no se veían luchas pero sí mucho descontento. [...] Alguien me dijo en Nueva York que el general Rodríguez tenía cuarenta mil hombres adiestrados junto a la frontera de Texas; que si me perdía al general Rodríguez, me perdía todo. ${ }^{10}$

Y es justamente eso lo primero que hace el narrador de Caminos sin ley: busca entrevistarse con el hermano del general Rodríguez, pues alguien le ha dicho que en ese momento se encuentra precisamente en Laredo. La imagen de la corrupción y la mentira, que recorre no sólo a las esferas gubernamentales, sino también a las fuerzas rebeldes, se manifiesta con fuerza en esa charla, y es la primera imagen que el cronista inglés tendrá de México, aun antes de internarse en el país. Cuando

${ }^{9}$ Raúl Ortiz, "Prólogo" a Caminos sin Ley, 1996, México, COnACulta, Mirada Viajera, p. 27.

${ }^{10}$ Graham Greene, El poder y la gloria-Caminos sin ley, 1998, México, Editorial Porrúa, p. 194. 
pregunta si podría entrevistarse con el hermano de Rodríguez, el contacto, sin el menor reparo, le contesta:

"Oh, sí [...]; le gustaría mucho verlo si prometía escribir algún articulito sobre su hermano". Así vivía su hermano, haciendo que los estúpidos periodistas norteamericanos escribieran sobre él. Luego mandaba ejemplares de los diarios a los terratenientes, hasta el sur de México -en Yucatán y Chiapas-, y entonces éstos creían que Rodríguez estaba haciendo algo y le mandaban dinero. ${ }^{11}$

Así, una rebelión mentida y usurpada por un vivillo generalito de provincia hace que lo que está ocurriendo en México aparezca a los ojos del escritor inglés (y por medio suyo a los ojos de los lectores del libro) bajo la figura de una corrupción extendida y generalizada en todo el país y que recorre por igual a las esferas oficiales y a los sectores rebeldes. Una sola víctima de todo ese extraño movimiento: los terratenientes usurpados. La decepción que la conversación con el contacto le ha provocado, hace que Greene desista de su deseo de encontrarse con Rodríguez, y en lugar de eso decide tomar un taxi e internarse en suelo mexicano. No tenía sentido seguir perdiendo el tiempo en Laredo con ofrecimientos espurios. A medida que el taxi avanza por tierras mexicanas, comienza a prefigurarse, ante la mirada del viajero, la imagen de un país sucio, oscuro, pobre, en comparación con su vecino del norte:

Este era México, aquello los Estados Unidos. La única diferencia era la suciedad y la oscuridad; en México no había tantas luces. El pueblo se llamaba Nuevo Laredo, para distinguirse del Laredo de Texas, pero como ocurre a menudo, el hijo parecía más viejo que el padre, más al tanto del lado mísero de la vida. Las calles eran oscuras y desiguales, la placita sofocante de vegetación, toda la vida del lugar transcurría detrás de las puertas giratorias de las cantinas y salones de billar. En el piso de mi habitación había una gran cucaracha muerta, y un olor rancio que provenía del W. C. ${ }^{12}$

${ }^{11}$ Ibid., pp. 200-1.

${ }^{12}$ Ibid., p. 201. 
El desencanto y la desilusión que le produce su primer contacto con la pobreza de las ciudades mexicanas pronto se extiende a otras zonas de la vida cotidiana: la comida, por ejemplo. La comida mexicana ha sido un motivo de elogio por más de un viajero europeo que ha recorrido el país. Italo Calvino, concretamente, la ha comparado con la comida china y la francesa; para él, las tres gastronomías más elaboradas y exquisitas que existen. ${ }^{13}$ Graham Greene, en cambio, derrocha ironía y sarcasmo cuando se refiere a ella:

El almuerzo era horrible, como todo lo que se come en sueños, insípido de una manera positiva, hasta el punto de que la misma ausencia de sabor resultaba repugnante. Toda la comida mexicana es así; si no tiene salsas picantes, no tiene nada, simplemente una multitud de platos colocados simultáneamente en la mesa, de modo que cinco se enfrían mientras uno come el sexto; trozos de carne anónima, un plato de frijoles, peces de los cuales hace mucho que se ha extraído todo sabor marino, arroz mezclado con algo que parece larvas de insectos (tal vez lo sea), una ensalada (peligrosa, nos advirtieron [...]), un montoncito de piel y huesos que llaman pollo [...]. Después de un tiempo el paladar pierde todo sentido discriminatorio; el hambre gana; uno llega, vagamente, hasta desear el almuerzo. Supongo que después de vivir bastante tiempo en México uno empieza a escribir como la señorita Frances Toor: "La cocina mexicana seduce tanto la vista como el paladar". ${ }^{14}$

Y lo mismo ocurre con la bebida. Al llegar a Monterrey, se hospeda en un hotel norteamericano, donde todos los huéspedes son norteamericanos. Se sienta con uno de ellos a la mesa y le ofrece algo de tomar: "Le hice beber un tequila -escribe Greene-, bebida alcohólica extraída del agave, una especie de ginebra bastante inferior". ${ }^{15}$ La comparación, y la valoración de lo comparado, es una experiencia absolutamente habitual en todo viajero. Sólo puedo explicarme la nueva realidad que tengo ante los ojos remitiéndola a realidades anteriores que guardo en la memoria. Sólo que, en el caso de Graham Greene, el resultado de esa

${ }^{13}$ Véase el ensayo "Italo Calvino: México: gastronomía y antropofagia" en Estudios, vol. VI, núm. 84, Primavera, 2008, pp. 85-93.

${ }^{14}$ Graham Greene, El poder y la gloria ..., op. cit., pp. 203-4.

${ }^{15}$ Ibid., p. 205. 
comparación es totalmente deplorable para México. Del otro lado de la frontera, en suelo mexicano, todo le parece "inferior" a Estados Unidos o Inglaterra: las calles polvosas, sin luz; los hoteles pestilentes y llenos de cucarachas (excepto los hoteles norteamericanos); la comida insípida, a no ser que se la atasque de picante; el tequila, una bebida bastante inferior a la ginebra. El ingreso a México parece ser, para el viajero inglés, una caída en una especie de submundo en el que todo resulta incomprensible, grosero, inconveniente: "paraíso infernal", lo ha llamado Ronald G. Walker en un ensayo en el que analiza la imagen que la novela inglesa moderna nos ha dejado de México. ${ }^{16}$

Hay algo, sin embargo, que compensa toda la fealdad y el mal gusto circundante: el sentimiento religioso del pueblo mexicano, su firme decisión de no abandonar sus arraigadas creencias, aunque esa decisión lo lleve a enfrentarse a las prohibiciones de su propio gobierno. Es miércoles de ceniza y el narrador decide visitar la Catedral de Monterrey. Allí recuerda una frase del presidente Lázaro Cárdenas: "Estoy cansado de cerrar iglesias y encontrarlas llenas. Ahora voy a abrirlas y a educar al pueblo, y dentro de diez años las encontraré vacías". ${ }^{17}$ Sin embargo, en ese momento, todo a su alrededor desmiente el aserto presidencial: la iglesia está llena de feligreses, niños, jóvenes, mujeres, ancianos desbordan el templo, más de doscientas cincuenta personas hacen fila para recibir, de rodillas, la cruz de ceniza en su frente: la fe no ha sido "educada" por la ciencia. Sigue manifestándose en los rezos de la multitud que, más que un murmullo, es un canto orgulloso y exultante. "Allí, sentía uno, estaba la verdadera religión; el tráfico continuo de la devoción". ${ }^{18} \mathrm{Y}$, en seguida, reflexiona: "empecé a pensar que después de todo Cárdenas se había equivocado". ${ }^{19}$

De Nuevo León, el cronista inglés se dirige a San Luis Potosí, que en ese momento sufre los efectos de una sublevación popular, que se supone dirigida por el general Saturnino Cedillo, viejo militante de las

${ }^{16}$ Ronald G. Walker, Paraíso infernal. México y la novela inglesa moderna, 1984, México, Fondo de Cultura Económica; véanse también los ensayos "D. H. Lawrence: México, la utopía imposible" y "Malcolm Lowry: México, las puertas del infierno" en este mismo libro.

${ }^{17}$ Graham Greene, El poder y la gloria ..., op. cit., p. 207.

${ }^{18}$ Ibidem.

${ }^{19}$ Ibid., p. 208. 
tropas revolucionarias, primero de Carranza, y luego de Villa; jefe de las operaciones militares contra los delahuertistas en 1923 y jefe de la División del Centro, que había combatido a los cristeros en Guanajuato, Jalisco y San Luis en 1926. Ahora, una vez más en armas en las sierras de Nuevo León, contra el mismo gobierno del que había sido secretario de Agricultura. "En estos momentos en que escribo -apunta el cronista en su cuaderno de viaje- se desarrolla una guerra de guerrillas entre esas mismas colinas; anteayer los rebeldes hicieron explotar un tren y el líder insurgente, el general Saturnino Cedillo, es perseguido de baluarte en baluarte por las montañas, y la censura impone silencio". ${ }^{20}$

Un instante después, el autor de Caminos sin ley expone las razones de esa persecución del líder rebelde:

En esos días, San Luis Potosí era un pequeño reducto capitalista dentro de un México socialista, regido menos por el gobernador que por el general indígena Cedillo, desde su estancia en las sierras, en Las Palomas. Hacía ya un año que se hablaba de rebelión en México, con Cedillo como posible líder; ${ }^{21}$ era uno de los viejos soldados indios de Carranza, el hombre que había sofocado la insurrección católica en Jalisco once años antes. También Cedillo era católico de nacimiento, pero no practicaba su religión; [...] la verdadera razón de que las leyes antirreligiosas no se respetaran en San Luis Potosí era la que el líder expresa ante un reportero norteamericano: "Tal vez yo no crea en todo ese asunto de la religión, pero los pobres la desean, y me encargaré de que les den lo que desean". 22

En el texto, se establece ya una evidente confrontación entre los ideales de Cedillo y los de Cárdenas, una confrontación que será sólo el inicio de la problemática central que Greene descubre en el abigarrado

${ }^{20}$ Ibid., p. 209.

${ }^{21}$ En realidad, el distanciamiento de Saturnino Cedillo con respecto al gobierno del que formaba parte se produjo en 1937, cuando sintió amenazadas sus propiedades en San Luis Potosí por la política agraria radical de Cárdenas, y renuncia a su puesto como secretario de Agricultura; hasta mayo de 1938 se levanta en armas contra el gobierno cardenista. Cfr. Lorenzo Meyer, "El primer tramo del camino", en Historia general de México, 1981, México, El Colegio de México, vol. 2, pp. 1231-2.

${ }^{22}$ Graham Greene, El poder y la gloria ..., op. cit., pp. 209-10. 
panorama político mexicano y que es lo que fundamentalmente le interesa discutir en su libro: la cuestión de la intolerancia religiosa. Si el planteamiento de Cedillo consiste en "darle al pueblo lo que el pueblo desea", el de Cárdenas apunta en sentido contrario: "educar al pueblo para que desee lo que el gobierno cree que es mejor para él". Y aquí no sólo la cuestión de la intolerancia religiosa pasa a primer plano: a través de ella aparece también la figura de un gobierno autoritario, despótico, dictatorial, que no respeta la voluntad de su gente, sus creencias más profundas, sus sentimientos más acendrados; él sabe de sobra lo que su pueblo necesita y está dispuesto a imponerlo a punta de pistola para sacarlo de su ignorancia. Por decisión gubernamental, la religión es oscurantista y sólo la luz de la ciencia podrá disolver las tinieblas de las conciencias. "Es muy típico en México, quizá en toda la raza humana -señala el escritor inglés-: la violencia a favor de un ideal, y luego el ideal se olvida y la violencia continúa", ${ }^{23}$

Entonces, decide entrevistarse con el general Cedillo, refugiado en alguna de sus fincas en Las Palomas, en San Luis Potosí, aunque tan sólo para descubrir que tampoco el general Cedillo está a las alturas de sus propios ideales: "darle a los pobres lo que los pobres desean".

Entra en contacto con un viejo profesor alemán que había intentado inútilmente aleccionar al general en los vericuetos de la gramática del inglés y del alemán, lo que lo había convertido en uno de los miembros de su círculo íntimo. El profesor acepta acompañarlo y viajan juntos hacia el bastión del líder indígena. La descripción que Greene nos ha dejado de él es la de un caudillo que no conoce otra ley que la suya propia, rodeado de sumisos soldados dispuestos a matar y morir no por una paga (no son mercenarios), sino por la devota subordinación al jefe, dueño de todas las mujeres que atienden la casa (le han advertido al joven periodista que no debe mirar a ninguna de ellas porque el general puede enojarse). El interior de la casa es de un mal gusto que golpea a la vista: atiborrada de muebles art nouveau, pieles de caimán, estatuillas de porcelana, una mesa de billar y una estampa en colores de Napoleón. En ese abigarrado y estrafalario ambiente, el general parecía un "hombre sin

${ }^{23}$ Ibid., p. 213. 
instrucción que se mantiene entre los instruidos". ${ }^{24}$ Le habían pedido que llevara las preguntas por escrito. En esa entrevista, el profesor leía las preguntas y el general le dictaba a un secretario las respuestas.

El ideario político del general Cedillo que nos presenta Graham Greene es tan ambiguo, tan ambivalente, con tan poca consistencia ideológica que parece una burla o una caricatura de cualquier ideario político: creía en la tolerancia religiosa ("Soy respetuoso de todas las creencias"), ${ }^{25}$ aunque aprobaba las escuelas socialistas y laicas que Cárdenas construía por todo México, pero rechazaba a sus maestros por su sectarismo al servicio de mezquinos intereses políticos. Aprobaba las nuevas leyes agrarias, pero no a los funcionarios que las aplicaban deshonestamente. Estaba en contra del fascismo y del comunismo, y preconizaba un gobierno democrático y parlamentario, aunque no sabía lo que significaban las palabras democracia y parlamento... En fin, lo que Greene nos hace ver, mediante la descripción de la débil y contradictoria plataforma política de Cedillo, es que todo su poder se basaba únicamente en las armas y en su carismática figura entre un pueblo ignorante y pobre. "Allí sentado, debajo de la bombita desnuda, junto a una mesa de billar, yo no podía seguir creyendo en los veinte mil soldados disciplinados que según se decía estaban preparados a obedecer su 1lamado". ${ }^{26}$

El desenlace del poderoso general Cedillo no se haría esperar. Al poco tiempo de esa entrevista,

Cárdenas pudo hacer su repentina y dramática aparición en San Luis, sin apoyo militar; arengó al pueblo en el bastión del enemigo, acusó a Cedillo de preparar una rebelión, y exigió el desarme del paisanaje. La guerra había comenzado. [...] Las Palomas fue ocupada, y Cedillo perseguido de refugio en refugio. Sus partidarios fueron encarcelados, hasta en el lejano sur, como en Las Casas, en el estado de Chiapas. Cerca de Puebla fusilaron a un general; la rebelión había terminado y el bandolerismo comenzaba. ${ }^{27}$

${ }^{24}$ Ibid., p. 219.

${ }^{25}$ Ibid., p. 221.

${ }^{26}$ Ibid., p. 222.

${ }^{27}$ Ibid., p. 223. 
Después de esa decepcionante entrevista con Saturnino Cedillo, Greene decide que no hay nada ya que lo retenga en San Luis Potosí, que no tiene ningún sentido prolongar su estancia allí, y decide continuar su viaje hacia los estados del sur (Veracruz, Tabasco y Chiapas), que era la región del país donde la persecución religiosa todavía continuaba con efectos verdaderamente desastrosos. Ese era el destino final de su viaje y sin más demora se dirigió hacia allí, aunque se reservó una par de días para una breve estancia en la ciudad de México, donde debía entrevistarse con un sacerdote a quien llevaba una carta de recomendación expedida por una organización católica de Nueva York. El sacerdote lo recibe en su casa y a los pocos minutos la conversación se centra en los problemas por los que en ese momento está atravesando la educación en México y, sobre todo, en la injerencia autoritaria y antidemocrática del Estado en el sistema educativo mexicano.

Me habló de la ley que prohíbe la educación religiosa en las escuelas, pero no prohíbe la enseñanza antirreligiosa; del decreto que convierte automáticamente toda casa donde se hayan reunido más de nueve personas con fines de religión en propiedad del Estado. [...] Aún las escuelas extranjeras -inglesas y norteamericanas- tenían que obedecer los decretos del gobierno en lo que se refería a enseñanza religiosa, y aceptar el programa oficial. Ninguna escuela podía utilizar maestros sin licencia oficial, y por lo tanto las escuelas privadas tenían que elegir a sus profesores de una lista proporcionada por el Secretario de Educación. Naturalmente [...] la Secretaría trataba de que sólo un color político estuviera representado en esa lista. Los maestros, una vez nombrados, formaban de costumbre un sindicato, y dirigían la escuela sin importarles el dueño. ${ }^{28}$

Cada época interpreta su propia historia de una manera distinta. Las herramientas y los criterios intelectuales cambian de una época a otra. Lo que en un momento se exalta de una manera vehemente como logros irrenunciables del progreso, puede ser cuestionado tiempo después desde una perspectiva intelectual distinta. Toda valoración de los hechos depende siempre de una circunstancia concreta y de los ins-

${ }^{28}$ Ibid., p. 233. 
trumentos ideológicos de que se dispone en ese momento para llevar a cabo esa valoración. Y en el México revolucionario de fines de los años treinta esos instrumentos ideológicos tenían un "color político" muy preciso y unos enemigos perfectamente delimitados.

No podemos negar que a fines de los años treinta el ideario político de Lázaro Cárdenas, así como el de otros líderes revolucionarios, estaba fuertemente marcado por planteamientos socialistas, que hoy en día resultarían insostenibles o al menos dudosos, incluso para los sectores más a la izquierda del espectro político. La política de nacionalización y la imposición de una educación laica para todo el país respondía a los planteamientos de las principales ideologías del momento, no sólo del fascismo y el socialismo, sino también de la propia ideología liberal que, en palabras de Keynes, postulaba la necesidad de un gobierno fuerte que controlara el mercado y de hecho toda la vida social. Los gobiernos autoritarios, basados no en la permisividad sino en la prohibición, se extendieron desde América a Europa (ya no digamos a África o Asia) en un abierto desprecio por las “débiles" ideas democráticas. Al mismo tiempo, el prestigio creciente de las nociones del progreso, la racionalidad y la técnica convertían a la religión en una práctica oscurantista, cuyo único objetivo consistía en mantener a la población en la ignorancia y el sometimiento. Estas concepciones de los años treinta se extendieron, al menos en México, hasta mediados de los años setenta, en que un nuevo modelo económico y una nueva idea de sociedad comenzaban ya a fraguarse. Hoy en día, no creo que ningún intelectual democrático, en ninguna parte del mundo, pueda estar a favor de un Estado interventor, de la nacionalización de las empresas privadas, del control de los mercados, de la censura, de la intolerancia religiosa o de cualquier concepción ideológica que no sea la concepción del Estado. Hoy en día, las nociones de libertad y tolerancia han terminado, felizmente, sustituyendo a los modelos ideológicos autoritarios que recorrieron la mayor parte del siglo XX.

Fueron esos modelos ideológicos autoritarios los que hicieron que, en México, los libros de Graham Greene sobre nuestro país (Caminos sin ley y El poder y la gloria) sufrieran la incomprensión y el escarnio 
por parte de la crítica de izquierda, que era el sector mayoritario de la crítica en México. Lázaro Cárdenas se había convertido ya en un mito intocable y sus medidas gubernamentales no podían ni siquiera discutirse, a menos que se estuviera dispuesto a afrontar la injuria y la exclusión por parte de esos críticos revolucionarios. Todavía a principios de este siglo, los ecos de esa incomprensión ideológica, con respecto a la obra de Graham Greene sobre México, seguían escuchándose en un sector de la crítica literaria mexicana ${ }^{29}$, incapaz de abandonar, o por lo menos revisar, los inveterados tópicos de la izquierda anticlerical y atea que dominó el ámbito intelectual mexicano durante casi todo el siglo XX.

Las conclusiones a las que llega Graham Greene, en 1938, sobre la educación y el Estado mexicanos van justamente en ese sentido: "La educación en México es fascista, o comunista, como queráis llamarla. No es democrática". ${ }^{30} \mathrm{Y}$ un poco más adelante, puntualiza: "El Estado [...] siempre el Estado. ¡Cuántos idealismos han contribuido a la construcción de ese tirano!"31

Decide no demorar su estancia en la ciudad de México. Abrumado por la "falsa elegancia" y la "falsa alegría" de la ciudad, el narrador de esta larga crónica decide continuar su viaje al sureste del país. Ya en el tren que debe conducirlo a Veracruz, Tabasco y Chiapas, el destino final de su viaje, se entera por el periódico del decreto de expropiación de las compañías petroleras extranjeras, firmado por el presidente Cárdenas. No tarda en calificarlo de "repentino y demente", pues el país se encontraba "estupefacto y aterrado por sus ahorros, mientras el peso bajaba vertiginosamente" 32 y se suspendía toda operación con divisas extranjeras.

Al llegar a Orizaba, el narrador corrobora que "no había iglesias abiertas en el estado de Veracruz, se decía misa secretamente, como en

${ }^{29}$ Cfr. Nair María Anaya Ferreira, La otredad del mestizaje: América Latina en la literatura inglesa, 2001, México, Facultad de Filosofía y Letras, Universidad Nacional Autónoma de México, pp. 259-91.

${ }^{30}$ Graham Greene, El poder y la gloria ..., op. cit., p. 233.

${ }^{31}$ Ibid., p. 234.

${ }^{32}$ Ibid., p. 249. 
Chiapas, en las casas de los particulares". ${ }^{33}$ La religión, una simple creencia que pertenecía al ámbito de la vida privada y a la que debía haber tenido derecho cualquier ciudadano, era censurada y perseguida, y había pasado a la clandestinidad: se la consideraba un delito social que debía ser castigado. El Estado, una vez más, el Estado omnipotente por encima de cualquier derecho individual. Y de pronto recuerda un acontecimiento que había ocurrido unos meses atrás:

[...] un domingo, en Orizaba, los agentes de policía siguieron a una criatura que había ido a misa; la niña huyó corriendo; dispararon, y la mataron; uno de esos estallidos repentinos e inexplicables de brutalidad, habituales en México. A los mexicanos les gustan los niños, pero alguna emanación de la maligna tierra azteca parece apoderarse de pronto del cerebro, como una ebriedad, y entonces sale a relucir la pistola. La consecuencia de esa muerte fue un estallido de fervor religioso en todo el estado de Veracruz; los campesinos entraron en las iglesias en la misma Veracruz, y cerraron las puertas con cerrojo e hicieron repicar las campanas; la policía no pudo hacer nada, y el gobernador cedió; las iglesias se abrieron. La indignación se agotó como un orgasmo; el sueño retornó a Orizaba. ${ }^{34}$

Aunque la remisión de la violencia gubernamental en México a su pasado azteca resulta excesiva y fuera de lugar, y sobre todo desvía el sentido de la requisitoria de Greene a una dimensión casi mítica, que hace de la violencia una especie de esencia del mexicano, lo que me parece que el escritor inglés quiere resaltar aquí son los efectos, a todas luces excesivos, de la intolerancia religiosa. Nada justifica (ni explica) la muerte de una niña inocente por el único "delito" de haber asistido a misa. Los agentes policiacos son sólo el instrumento ciego al servicio de una ideología intransigente y fanática, sus simples ejecutores; lo que está detrás de ese acto de barbarie es la razón de Estado a la que ellos tienen que obedecer, una razón de Estado que en la mayoría de los casos actúa de una manera mucho más irracional que aquello que

${ }^{33}$ Ibid., pp. 251-2.

${ }^{34}$ Ibid., p. 252. 
quiere combatir. Lo que parece subrayar Greene en este fragmento es que el fanatismo no es siempre ni necesariamente religioso, que hay un fanatismo mucho más peligroso: el fanatismo de Estado. Y en la lectura que el autor hace de este período de la historia mexicana, los papeles se invierten: la irracionalidad no estaba de parte de los Cristeros, que tenían derecho a su fe y a las prácticas de su fe; la irracionalidad estaba de parte del Estado mexicano, que no tenía ningún derecho de perseguir las creencias particulares, cualquiera que éstas fueran, de sus ciudadanos.

Después de una breve estancia en Veracruz, el viajero decide continuar su viaje a Tabasco y Chiapas. No sabe exactamente lo que habrá de encontrarse allí, pero la travesía en barco es larga: cuarenta y dos horas, y tiene el tiempo suficiente para recuperar las anécdotas que le han contado sobre el estado de Tabasco y, en particular, sobre Garrido Canabal, su gobernador durante la persecución religiosa iniciada, doce años antes, por el presidente Calles. Y en ese recuerdo la imagen de la intolerancia y de la dictadura absoluta e irrestricta se sitúa en el centro:

Esto era Tabasco, el estado puritano, pantanoso, aislado, de Garrido Canabal. Garrido -así decían- había destruido todas las iglesias; había organizado una milicia de "camisas rojas", y hasta les había hecho cruzar la frontera de Chiapas, persiguiendo iglesias y sacerdotes. Allanaban las casas de los particulares en busca de emblemas religiosos, y la cárcel era el castigo para los que los poseían. Un joven que conocí en la capital -amigo de la familia de Garrido- estuvo tres días encarcelado por llevar una cruz bajo la camisa; el dictador era incorruptible. [...] Ahora Garrido está en Costa Rica, pero su política continúa. ${ }^{35}$

Doce años después de la persecución religiosa de Calles, ahora bajo la presidencia de Lázaro Cárdenas, nada ha cambiado en el sureste mexicano. Y el viajero no tardará en constatarlo. Su primer contacto con la violencia gubernamental ocurrirá la misma noche de su llegada a Tabasco, incluso antes de abandonar el barco que lo condujo hasta allí. Cuando el barco arriba a puerto, un grupo de agentes de la aduana,

${ }^{35} I$ Ibid., pp. 263-4. 
pistola en mano, lo registra de punta a cabo, no sólo las mercancías que transporta, sino incluso el equipaje de los pasajeros y a los pasajeros mismos, como si se estuviera viviendo un declarado estado de guerra. Nunca les dijeron lo que buscaban, nunca les dieron la más mínima explicación: las autoridades policiacas no tenían por qué explicar nada. La ley estaba de su parte y, ante la ley, todo ciudadano era un presunto delincuente.

Ante ese acto de violencia e impunidad por parte de las autoridades aduaneras, el narrador decide que sería un acto aventurero e irresponsable ingresar a la ciudad a mitad de la noche, precisamente porque sería como ingresar a un territorio en el que el más mínimo derecho individual estaba ausente. Elige pasar la noche en el barco, aunque allí sólo había dos lugares donde pernoctar: la cubierta, en la que sería devorado por los mosquitos y se exponía a contagiarse de malaria, o bajar al camarote y soportar, durante lo que quedaba de la noche, un calor insoportable. "El único ojo de buey estaba cerrado por temor a los ladrones". ${ }^{36}$ Eligió la segunda opción, que lo protegía no sólo de los mosquitos, sino también de los ladrones, y pasó la noche en vela, sudando y secándose el sudor con una toalla sucia.

A la mañana siguiente, con el sudor y el sueño pegados al cuerpo, ingresa en una ciudad a todas luces hostil. No se atreve a confiar en nada ni en nadie. Hasta ahora la única imagen que tiene de Tabasco es la de un territorio dividido entre ladrones voraces y policías corruptos y abyectos, una tierra sin ley o donde la ley está al servicio de la infamia. Lleva una carta de recomendación para un hombre que habrá de darle cobijo durante su estancia en Villahermosa, y nada más bajar del barco se dirige hacia allí. En la conversación que sostiene con ese hombre anónimo, o a quien Graham Greene decide mantener en el anonimato quizá como una medida de precaución hacia él, se entera de la situación actual de la Iglesia en Tabasco: "En Tabasco no quedaba un solo cura, [...] ninguna iglesia en pie, excepto una a ocho leguas de allí, utilizada ahora como escuela. Antes había un cura del otro lado de la frontera de Tabasco, en Chiapas, pero los pobladores le habían dicho que se fuera, porque ya no podían seguir protegiéndolo". ${ }^{37}$

${ }^{36}$ Ibid., p. 264.

${ }^{37}$ Ibid., p. 271. 
Esa imagen del cura perseguido y errante golpeará con fuerza la conciencia del escritor inglés. Y doce años más tarde, en 1940, la recuperará como la imagen central y desencadenante de la historia de su gran novela sobre la persecución religiosa en México: El poder y la gloria, y a la que John Updike consideró "la obra maestra de Graham Greene y la que le otorgó la más amplia acogida entre sus lectores y la estimación de la crítica".38

Pero ahora nos estamos internando, de la mano del escritor inglés, por los Caminos sin ley que lo han conducido al sureste mexicano y, concretamente, a la ciudad de Villahermosa. La descripción que hace Greene de Villahermosa acentúa su abandono, como si con las iglesias y los curas se hubiera ido de la ciudad todo signo de vida, de esperanza, y sólo quedara el fango, las moscas, la suciedad, la descomposición. Sin iglesias ni sacerdotes, ahora las comisarías y la policía habían raptado a la ciudad:

La policía era la capa más baja de la población; para encontrar algo de honradez, había que escrutarla en las caras de los hombres y las mujeres que esperaban ser multados o insultados. Uno experimentaba una sensación abrumadora de brutalidad y de irresponsabilidad. [...] Estos eran los hombres que algunas semanas más tarde dispararían contra una multitud de campesinos indefensos que trataban de orar en las ruinas de una iglesia. ${ }^{39}$

Y un poco más adelante, después de haber pasado un día completo en Villahermosa, preparando su viaje hacia Chiapas y como despidiéndose de esa ciudad tan inhabitable como una cárcel, Greene reflexiona: "Es curioso cómo el lugar más tétrico empieza después de veinticuatro horas a parecernos nuestro hogar. [...] Y ya es algo tener alguna emoción en un lugar como Villahermosa, aunque sólo sea el miedo". ${ }^{40}$

${ }^{38}$ John Updike, "Introducción”, en Graham Greene The Power and the Glory, London, Random House, Vintage, 2001, p. v. (TM).

${ }^{39}$ Graham Greene, El poder y la gloria ..., op. cit., p. 273.

${ }^{40}$ Ibid., p. 274. 
Al fin, el viajero decide abandonar Villahermosa y dirigirse a Chiapas. Ya en el avión, mientras contempla por la ventanilla los edificios grises de la ciudad, nos da una última imagen que abarca todo el estado de Tabasco, una visión que resulta dura y conclusiva sobre su breve estancia allí: "Abajo, muy lejos, se extendía Tabasco, el estado sin Dios, el paisaje del terror y del cautiverio de un hombre perseguido; bosque y agua, sin caminos, y en el horizonte las montañas de Chiapas, como el muro de una cárcel". ${ }^{41}$

La situación que el narrador habrá de encontrar en Chiapas no hace sino repetir lo mismo que ha vivido ya en Tabasco: las iglesias cerradas; los sacerdotes perseguidos; la fe exiliada de las ciudades, refugiada en las selvas o las montañas; la figura del maestro, cuya misión consiste en adoctrinar al pueblo en la nueva doctrina socialista, que habrá de redimirlo del oscurantismo religioso y de la sumisión a la Iglesia, $\mathrm{y}$, como colofón de todo eso, los militares, recorriendo ufanamente las calles de las ciudades. Pero ahora hay un elemento más que golpea con fuerza la conciencia del escritor inglés: la pobreza, la miseria de la población indígena en torno suyo aparece ahora agudizada, acentuada de una manera que ni siquiera podía imaginar en tierras tabasqueñas:

Se dice que cuando el año es malo los indios se mueren de hambre a centenares, pero nadie lo sabe; se retiran como animales heridos a la selva y a las montañas, y comen frutas salvajes, tratando de resistir mientras pueden, pero sin buscar la compasión de nadie. Y en las montañas, como pude ver más tarde, tienen lo que la gente de Yajalón no posee, sus cruces, sus lugares de adoración; el cristianismo existe allí como ellos mismos, salvaje, aislado e incomprensible. ${ }^{42}$

Las selvas, las montañas son allí el único refugio que les queda a los indígenas para sobrevivir y hacer sobrevivir a su fe, a sus creencias más ancestrales a las que no están dispuestos a renunciar en aras de la nueva fe socialista que el gobierno autoritario y centralista intenta imponerles. Hay un rumor que traduce un deseo generalizado en todo el estado, un sueño que alienta la voluntad del pueblo chiapaneco: "la

${ }^{41}$ Ibid., p. 285.

${ }^{42}$ Ibid., p. 306. 
esperanza de un levantamiento que separaría los estados de Chiapas, Tabasco, Yucatán y Quintana Roo del resto de México y de una alianza con Guatemala, país católico. Todos los proyectos contra el gobierno de México se confunden de algún modo con este sueño". ${ }^{43}$

Se trataba, sin embargo, de un sueño irrealizable. El gobierno central no estaba dispuesto a prescindir de casi la mitad de país en favor de una libertad religiosa que tampoco respetaba. No eran tiempos democráticos los que vivía México, en los que cada ciudadano debía disfrutar del derecho a creer y pensar libremente, sino más bien tiempos de imposición y sometimiento a una verdad, la verdad del Estado, porque sólo el Estado sabía, con la claridad de que lo dotaba el "pensamiento científico", lo que era conveniente para sus ciudadanos. La persecución religiosa llevaba ya doce años, al menos, recorriendo el país: primero con Calles, en el centro de la República; ahora con Lázaro Cárdenas, en casi todo el sureste. El sueño de verse libres de la inmensa sombra de ese "ogro filantrópico", como lo calificaría Octavio Paz años después, era sólo un sueño imposible.

Después de una interminable semana de espera por ese avión que debía conducirlo de Yajalón a San Cristóbal de las Casas, el narrador decide hacer el viaje a lomo de mula entre las montañas y los desfiladeros de Chiapas, bajo una lluvia intensa que no cedió durante los cuatro días y las cuatro noches que duró el trayecto, durmiendo en jacales, entre ratas, o a la intemperie, bajo la lluvia. Al llegar al fin a San Cristóbal, constata lo que le habían dicho en Yajalón antes de iniciar el viaje: en San Cristóbal las iglesias todavía seguían abiertas, pero no se permitía la entrada a los curas. Sobrevivía el edificio, pero no su sacra función; la misa estaba prohibida y las iglesias no pasaban de ser exiguas ruinas en medio de la ciudad. "Le pregunté [a una mujer] dónde se podía oír misa - escribe Greene-, y mandó a su hijita para que me mostrara una casa donde dirían misa durante toda la Semana Santa; una casa cualquiera, en una calle lateral, una puerta cerrada, nada que indicara la presencia de Dios". ${ }^{4}$

${ }^{43}$ Ibid., p. 304.

${ }^{44}$ Ibid., p. 324. 
Pero tampoco allí se podía estar seguro. Se trataba de una actividad penada por la ley y, por lo tanto, tenía que llevarse a cabo de manera clandestina. La policía estaba al tanto de lo que ocurría en cada calle, en cada casa, y sabía sacar provecho de ello. Muchos de los rumores que corrían en San Cristóbal se referían precisamente a la definitiva corrupción de la policía, a la facilidad con la que se la podía sobornar, pero cuando el soborno no era suficiente "allanaban alguna casa donde se decía misa, multaban a toda la concurrencia, y se llevaban al cura a la cárcel, como rehén, para que pagaran el rescate". ${ }^{45}$

Al día siguiente de su llegada a San Cristóbal, decide entrevistarse con un alemán, gerente de un banco, del que le han dado algunas referencias, con el fin de informarse sobre lo que está ocurriendo en la región. De camino a casa del banquero, constata la tensión que recorre las calles y las plazas: la Catedral estaba cerrada con enormes trancas en las puertas y por las calles se paseaban, impunes, varios grupos de pistoleros. Observa también cómo unos panfletos rojos pasan de mano en mano entre la gente. En ellos, se avisa a la población que el general Pineda se dirige a la ciudad. Pineda era el general católico que proyectaba la separación de Chiapas del resto de México y su anexión a Guatemala. Aunque esto era sólo un rumor, también es cierto que todo rumor nace de un deseo colectivo. Y ese deseo nacía, sin duda, del rechazo a la represión religiosa que sufría el pueblo chiapaneco y de su decidida voluntad de creer y pensar libremente.

Pineda había sido presidente municipal de San Cristóbal de las Casas y bajo su administración se habían llevado a cabo obras sanitarias y de irrigación que habían beneficiado a todo el municipio, pero hacía unos meses habían llegado pistoleros de Tuxtla, lo habían echado de la Presidencia y, en su lugar, habían instalado a un amigo cercano del gobernador de Chiapas. Pineda se había dirigido a la ciudad de México y había logrado obtener un amparo que le permitía volver a ocupar la presidencia de San Cristóbal. Hacía unos días había anunciado a sus amigos que estaba dispuesto a volver. Los amigos "lo esperaban en cualquier momento; los pistoleros lo acechaban". ${ }^{46}$

${ }^{45}$ Ibidem .

${ }^{46}$ Ibid., p. 326. 
El tan anhelado regreso de Pineda no se produce nunca; lo que sí se produce, en cambio, es un considerable incremento de la tensión y de la hostilidad en la ciudad. Una hostilidad que ahora, de pronto, y sin que hubiera motivo aparente para ello, se ve dirigida hacia él, ese gringo indolente, que no tenía nada que hacer sentado en un banco de la plaza central:

Me senté en un banco, esperando, hasta las siete. Por supuesto, [Pineda] no llegó, ni esa ni ninguna otra noche. Lo único que ocurrió fue que la atmósfera de hostilidad se espesó, y se dirigió contra mí. Un grupo de borrachos pasó y volvió a pasar, burlándose de mí; cada uno tenía su revólver debajo del chaleco, de modo que lo único que podía hacer era quedarme sentado, como una solterona púdica, simulando que no los oía. [...] Desde esa noche, la hostilidad no cesó nunca; ya no podía sentarme en la plaza unos minutos, sin recibir un insulto. Me ponía nervioso; era como ser el niño odiado de la escuela. ${ }^{47}$

En la última imagen que Graham Greene nos da de su estancia en San Cristóbal de las Casas se resume no sólo todo su viaje por el sureste mexicano, sino también la imagen de una represión y una persecución que abarca tanto a la Iglesia como la toda la vida social de la región, y en la que la policía y el ejército son el instrumento del que se vale el gobierno revolucionario de Lázaro Cárdenas para mantener a la población oprimida y esquilmada.

Sin embargo, toda ese clima de represión generalizada en la región ha producido precisamente el efecto contrario al que se esperaba: en lugar de reducir o disolver el sentimiento religioso de los ciudadanos ha terminado por incrementarlo y enraizarlo. Y ahora ese sentimiento religioso constituye un arma de lucha y enfrentamiento entre gobernados y gobernantes, como doce años antes durante la administración de Calles, en el centro del país. Las medidas gubernamentales que suponían liberar a la población de los dogmas religiosos y el oscurantismo de la Iglesia, en favor de una educación racional y científica, han terminado produciendo una rebelión popular, apoyada en la Iglesia, contra

${ }^{47}$ Ibid., pp. 327-8. 
el gobierno revolucionario. Y es que no es posible, es más bien una contradicción en los términos, es sin duda el acto más irracional y bárbaro, tratar de imponer la razón y la ciencia.

En su largo viaje de regreso a la ciudad de México desde San Cristóbal de las Casas, el cronista inglés utiliza cualquier medio de transporte a su alcance: mulas, aviones, trenes. No lleva ningún libro para entretener el viaje y, en el tramo que va de Oaxaca a Puebla, en un tren tan lento y sucio como una mula, decide, a manera de corolario del viaje, hacer algunas anotaciones en su cuaderno. Una de ellas dice:

Los sostenedores de la revolución proletaria se jugaron la vida por una filosofía. Es la única razón que tienen para continuar la lúgubre tarea de vivir. Uno no puede esperar que reconozcan, ni siquiera ante ellos mismos, que Rusia ha demostrado ser un fracaso -o México-, sin el consuelo de una dramática conversión a alguna otra religión. Nadie puede soportar la vida sin una filosofía. ${ }^{48}$

Al final de Caminos sin ley, Graham Greene concluye la crónica de su viaje a México con dos palabras que intentan, en una suerte de síntesis perentoria aunque necesaria, expresar el sentimiento de todo lo vivido allí durante esas largas seis semanas: "un país de decepciones y desesperación". 49

${ }^{48}$ Ibid., p. 345.

${ }^{49}$ Ibid., p. 351. 